\title{
Comentários sobre a tendência secular da tuberculose
}

\author{
Dina Czeresnia Costa*
}

Este trabalho busca revisar uma discussão realizada por vários autores sobre a tendência secular da mortalidade por tuberculose em diferentes formações sociais. Observamos entre os autores uma concordância: 1 .) em relação à influência da melhoria do padrão de vida das populações na queda da mortalidade pela doença; $2:$ ) a respeito da aceleraçāo desta queda, a partir da introdução de quimioterapia eficaz. Vários autores consideram também a hipótese de ter ocorrido uma epidemia da doença no início do século XIX em espaços como a Inglaterra e a cidade do Rio de Janeiro via condicionantes sociais obviamente distintos e outros que nāo trabalham com esta hipótese na tentativa de explicar as flutuaçōes na "tendência secular" da enfermidade.

\section{INDUSTRIALIZAÇĀO E TUBERCULOSE: O CA- SO INGLESS}

As doenças se manifestam de diferentes maneiras em diferentes épocas e sociedades. Tendem a refletir as diversas relações entre os processos sociais e as condiçōes de existência de grupos populacionais e classes sociais. Especialmente a tuberculose é conhecida como uma doença muito suscetível às variaçōes nas condiçōes de vida das populações. O seu padrão epidemiológico variou muito no decorrer do tempo e em diferentes sociedades.

A tuberculose é considerada atualmente uma doença crônica e de evolução lenta. Cockburn aponta, no entanto, para o caráter rapidamente progressivo que a doença assume em populações que estão entrando pela primeira vez em contato com o bacilo da tubercu. lose. Ele sugere, por exemplo, que quando a tuberculose apareceu, pela primeira vez, na Europa o seli perfil foi provavelmente epidêmico ao contrário do padrão encontrado hoje. (2)

Cockbum afirma que as populações tendem a ad-

* Pesquisadora visitante do Departamento de Epidemiologia $e$ Métodos Quantitativos em Saúde - Escola Nacional de Saúde Pública - FIOCRUZ quirir uma resistência aos agentes patogênicos das doenças. Os indivíduos que sobrevivem às infecçöes e tornam essa resistência hereditária levam as populaçōes a desenvolverem uma resistência genética a esșes agentes. (2)

Cadernos de Saúde Pública, RJ, 4 (4): 398-406, out/dez, 1988 
Cabe chamar atenção, porém, que os padrões de resistência que determinam a suscetibilidade às infecções são modificados pelas condições de vida.

Segundo René e Jean Dubos, na Inglaterra, a mortalidade por doenças pulmonares parece ter sido muito alta em torno de 1650 , caindo então, lentanente, por muito tempo, até subir novamente na primeira metade do século XIX, em decorrência da conhecida degradação do padrão de vida, durante a revolução industrial. (3) Berlinguer sublinha também o crescimento da tuberclose no início da revolução industrial, quando o desenvolvimento da produção fabril e a conseqüente urbanização levaram os trabalhadores a morarem aglomerados e conviverem com condições de trabalho insalubres e desgastantes. (1)

Grigg relaciona o crescimento populacional e o início da industriailização na costa leste dos EUA, no período posterior a sua independência, com o pico de mortalidade por tuberculose que teria ocorrido em torno de 1800 nas áreas urbanas da costa Atlântica. Segundo ele, a taxa de mortalidade excedeu 100 e pode ter alcançado $1500 / 100000$. Já as cidades do sudoeste americano, menos industrializadas, registrariam um crescimento, em menores proporçōes, da mortalidade por tuberculose somente a partir da segunda metade do século XIX. (4)

Segundo Dubos, esse aumento da tuberculose nas sociedades capitalistas no séc. XIX foi conseqüência das tragédias sociais que se seguiram na esteira da revoluçã̃o industrial. A maioria dos indivíduos recrutados para o trabalho industrial já era pobre na vida rural, porém estava adaptada ao seu meio social. $O$ trabalho na indústria em condiçōes insalubres, o stress da nova ordem e a concentração populacional favoreceram a extensão da infecção tuberculosa e o desenvolvimento da doença. (3)

Essas especulações em torno da incidência da tuberculose no século XIX remetem à questão da dificuldade do estudo da tendência secular da tuberculose, devido aos problemas relacionados à confiabilidade dos dados. Os principais são: a descontinuidade da forma de registro; mudanças nos métodos diagnósticos; informaçöes imprecisas e de fontes diversas. O aumento da tuberculose no início do séc. XIX, por exemplo, é uma hipótese sugerida por vários autores, que se baseiam em relatos significativos da época e em registros fragmentados. No entanto, os dados disponíveis sobre a mortalidade causada pela doença são, em geral, a partir da segunda metade do século XIX e registram uma queda contínua da doença.

Mckeown aponta para o fato de que o registro de mortalidade só se instituiu nacionalmente na Inglaterra após 1838 , e, já a partir de então, foi verificada 
uma queda de mortalidade causada pela tuberculose. Ao analisar as possíveis causas dessa queda, Mckeown sustenta: que não parece ter havido variação na virulência do bacilo; que em relação à resistência humana, o fato da população da Inglaterra ter sido fortemente exposta à infecção por muitos séculos tornam improvável que a seleção genética seja a principal razăo para a tendência de queda encontrada. Ele atribui a queda da tuberculose a mudanças no meio social, especialmente à melhoria da nutrição registrada na Inglaterra no século XIX. (8)

Mckeown, no entanto, não trabalha com a hipótese defendida por vários autores de que houve uma epidemia de tuberclose no início do século XIX, se a considerarmos como verdadeira, a queda rápida que se registrou imediatamente após poderia ser devida também a um aumento de resistência imunológica da população. Segundo o próprio Mckeown, "a constituição imunológica de uma geração é influenciada amplamente pela experiência de mortalidade daqueles que a precederam. Isto foi particularmente verdade no passado quando a maioria das pessoas morria de doenças infecciosas sem se reproduzirem".(9) Com efeito, a curva de mortalidade por tuberculose na Inglaterra apresenta uma inclinação maior na primeira década após o início do registro, mantendo após uma queda contínua em menor ritmo, que se acelera a partir de 1940. (Gráfico I).

\section{Gráfico I}

Tuberculose Respiratória, 'Taxa de Mortalidade Anual Média Inglaterra e Gales

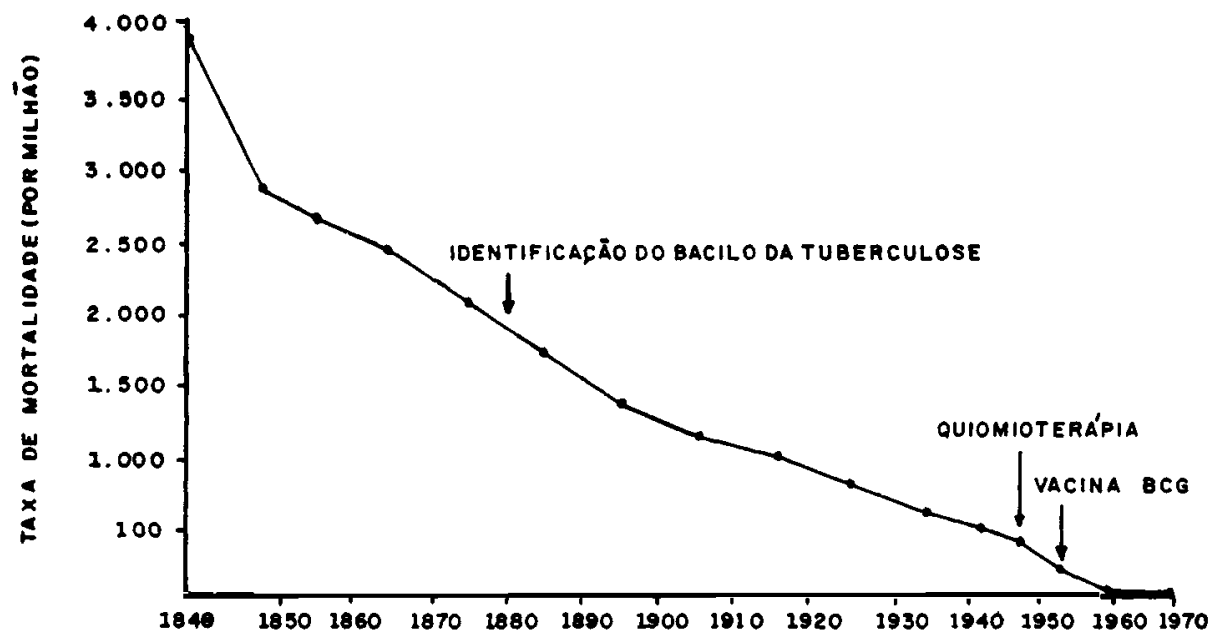

in: T. Mckeown C. C. R. Iowe, Introdución a la Medicina Social, México, Siglo Veintiuno, 1981. 
Trabalhando com uma formação social muito distinta, os autores que analisaram recentemente a curva secular da mortalidade por tuberculose no Rio de Janeiro também apresentam hipóteses diferentes em relação às causas da queda da doença.

Ruffino e Pereira apontam nesta curva três períodos: o primeiro até 1885 , quando houve uma queda em ritmo mais acelerado em relação aos segundo (entre 1885 e 1945) que manteve uma tendência de queda, porém em ritmo menor e o terceiro a partir de 1945, quando o ritmo de queda voltou a se acelerar. (Gráfico 2) (10)

\section{Gráfico II}

Mortalidade por Tuberculose (Todas as Formas) Rio de Janeiro, $1860-1877$

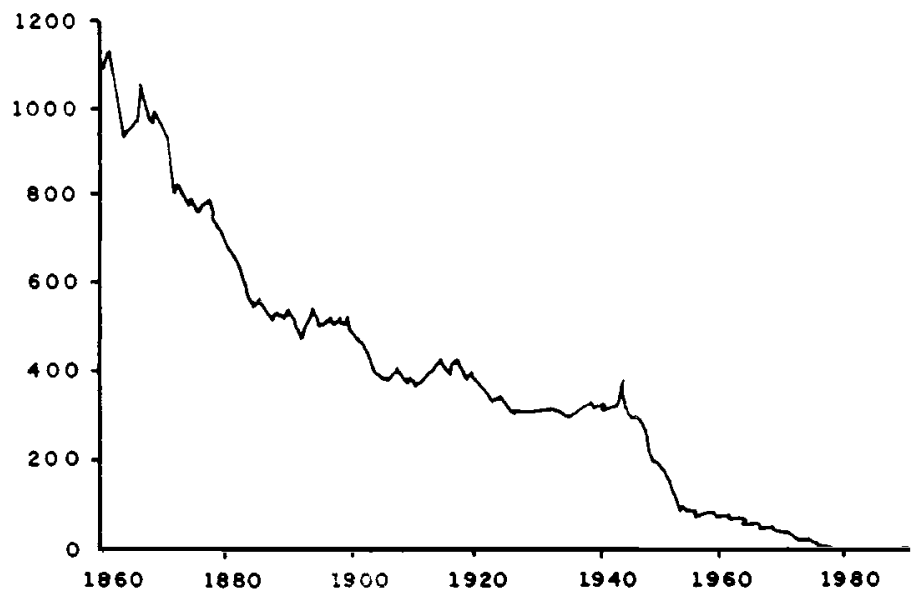

in: A. N. Ruffino,' J. C. Pereira, "Mortalidade por tuberculose e Condiçōes de vida: O caso do Rio de Janeiro". Saúde em Debate, Rio de Janeiro (17):27 34, 1981.

Buscando identificar as causas que estão influenciando esta queda, os autores destacam no primeiro período as alteraçōes ocorridas na economia cafeeira e o conseqüente processo de europeização e "embranquecimento" da cidade, mudanças na arquitetura e diminuição do número de habitantes por residência. Já no segundo período, analisando o processo de desenvolvimento da indústria e também da economia cafeeira acreditam que "os fatores e condiçöes intervenientes melhoraram menos significativamente as condiçōes de existência, quando as comparamos com tempos ante. riores". A partir de 1945, além de possíveis melhorias no padrão de vida da população ressaltam a importân- 
cia da utilização da quimioterapia contra tuberclose na aceleração da queda da mortalidade pela doença. (10)

Guimarães tem como hipótese, que o grande decréscimo apresentado pela curva do Rio de Janeiro no seu início seria o lado direito de uma grande curva epidêmica. Para ele, a tuberculose recrudesceu enormemente durante a primeira metade do século XIX, devido principalmente ao novo padrão demográfico e de urbanização criado na cidade com a vinda da corte de Portugal para o Rio de Janeiro e com a intensificação do tráfico de escravos, trazendo da Europa maior número de doentes e da Árica um grande número de indivíduos suscetiveis que viviam em péssimas condições. (5)

A tendência secular da mortalidade por tuberculose na Inglaterra e Rio de Janeiro apresentam diferenças que expressam os seus processos sociais obviamente distintos. Apesar dos dados não se corresponderem em relação a forma clínica, podemos observar que a magnitude da doença no Rio de Janeiro sempre foi muito maior que na Inglaterra.

\section{Gráfico III}

Taxa de Mortalidade por Tuberculose (/100.000) Riode Janeiro (Todas as Formas)

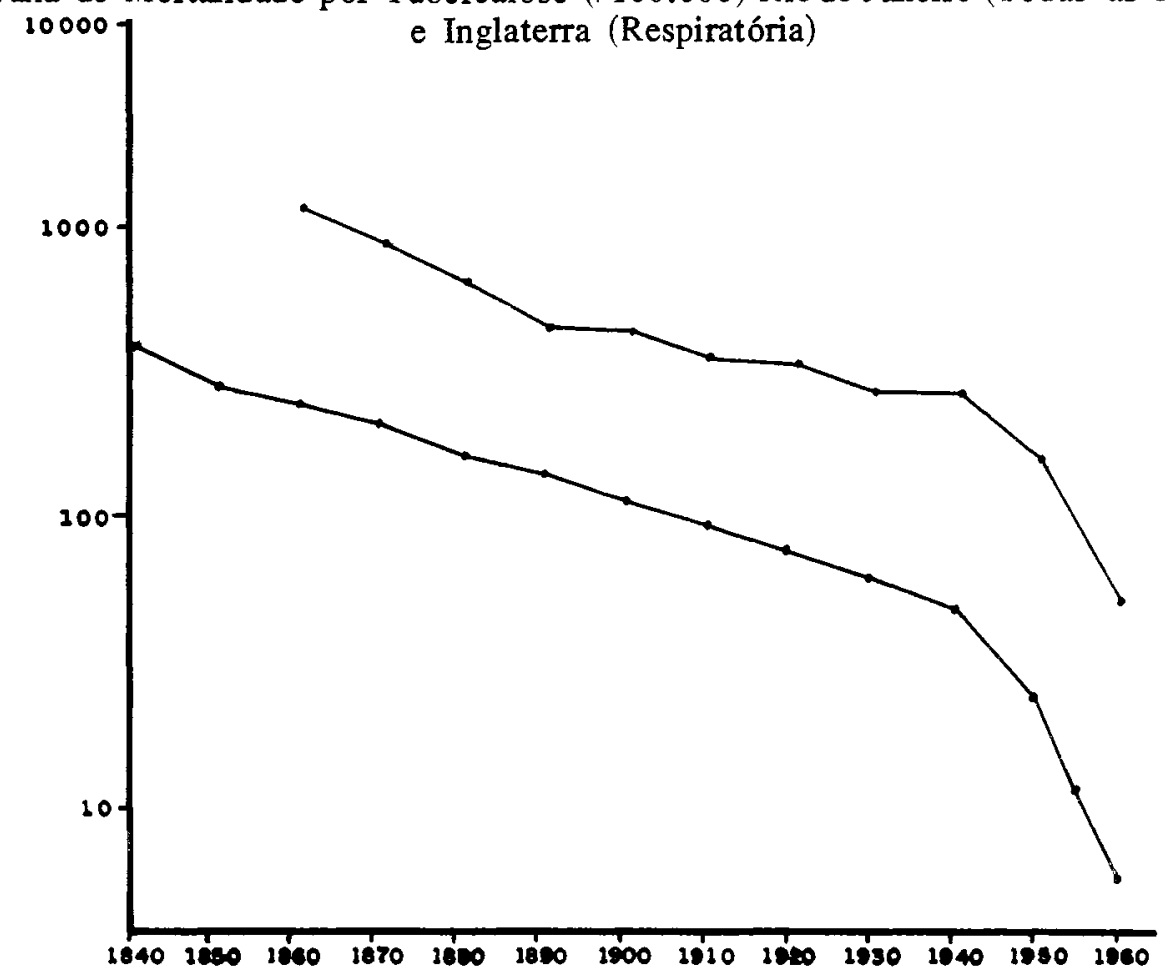


No entanto, observamos algumas semelhanças nas curvas, que se tomam mais nítidas quando as adaptamos para a mesma escala (gráfico III). Ambas apresentam uma tendência de queda inicialmente mais rápida. No Rio de Janeiro este período é mais nítido. $\mathrm{Na}$ Inglaterra somente entre 1840 e 1850 , porém poderia estar ocorrendo em período anterior ao registro. Em ambas as curvas o ritmo é de queda, que se acelera a partir de 1940. No Rio de Janeiro entre 1850 e 1940 a queda é mais lenta que na inglaterra.

DEGRADAÇÃO DAS CONOICCÕES DE VIDA E PA. DRĀO EPIDÊMICO

Durante o século XX, a tuberculose manteve um: tendência de queda em todos os locais que se ter: registro. No entanto, durante as duas grandes guerras mundiais houve um aumento da mortalidade por tuberculose em vários países europeus, que logo após. término do conflito, reassumiram suá tendência anterior. Este fato é caracterizado como sugestivo da grar. de vulnerabilidade da doen a às variaçōes das condiçōes de vida. (3) Deve-se îevar en conta, no entanto, que as condiçōes excepcionais de uma guerra podem interferir num aumento de registros de óbitos com erros de diagnóstico, num período em que a mortalidade é muito maior em geral.

Nesse contexto, Dubos destaca a importância da variação das condiçōes de alimentaçāo sobre a mortalidade por tuberculose, ao comentar que a Dinamarca registrou um aumento marcado na riortalidade entre 1914 e 1917. Segundo ele, nesse período, apesar de não ter entrado na guerta, houve uma redução significativa no consumo de carne na Dinamarca. Em 1917 a oferta da carne se normalizou e a tendência da mortalidade reassumiu sua queda anterior. (3)

Dubos ressal cu a condiçones de vida no aumento nomalidade por tubercuiose em povos ccibus: conc altamente resistentes doença. Ele cita a mit.jiutse entre os judeus de Var. sóvia que era meris ‘n ql entre os rẩo judeus. DLrante a I Guerra, a istali lade subin nos dois grupos permanecendo menc th os judeus. Durante a $D$

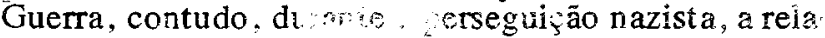
ção se inverteu. Os dados cuados por Dubos foram:

Taxa de Mortalidade por Tuberculose em Varsóvia (Por 100.000)

\begin{tabular}{lccc}
\hline & 1938 & 1940 & 1942 \\
\hline Judeus & 71 & 205 & 601 \\
Não Judeus & 186 & 377 & $425(3)$ \\
Risco relativo & 0,38 & 0,54 & 1,41 \\
\hline
\end{tabular}

Cadernos de Saúde Pública, RJ, 4 (4): 398-406, out/dez, 1988 
No final da década de 40 , com a introdução da quimioterapia, como já foi comentado, a tendência de queda da mortalidade se acentuou. Pela primeira vez uma medida de controle específica pode ser identiGicada como causa de diminuiçăo da mortalidade pela doença que já vinha declinando há mais de um século nas sociedades urbanas ocidentais.

\section{CONCLUSÃO}

A existência de uma relação entre a mortalidade por tuberculose e as condições gerais de vida de uma população parece óbvia, e realmente a tuberculose é considerada classicamente uma doença social. No entanto, as diferentes interpretaçóes dadas à curva secular da doença, valorizando ou não determinados processos específicos que podem estar ocorrendo, levam a conclusōes bastante diferentes.

No caso da Inglaterra, esta questão tem implicações sobre a interpretação das conseqüências sociais da industrialização capitalista, a partir do século XIX. Por exemplo, Mckeown ao analisar a doença a partir do início do registro, sem especular sobre o provável aumento epidêmico de casos no início do século, favorece uma interpretação otimista da revolução industrial.

A discussão sobre o processo de industrialização e seu impacto sobre o padráo de vida da classe trabalhadora inglesa envolve a opinião de uma série de historiadores importantes que se dividem, segundo Hobsbawn, numa escola clássica "pessimista" que inclui Ricardo, Malthus, Marx e Toynbee e uma escola moderna "otimista" (Clapham, Ashton, Hayek). (6)

Já as diferentes interpretações da curva secular da tuberculose no Rio de Janeiro, podem apontar, por exemplo, para hipóteses distintas em relação ao efeito do processo de migração, urbanização e expansão da industrialização, a partir do final do século $\mathrm{XIX}$, sobre as condiçōes de vida da populaçāo da cidade.

Se considerarmos que ocorreu uma epidemia de tuberculose na primeira metade do século XIX, a hipótese da influência da melhoria das condiçōes de vida na queda da doença não deixaria de ser válida, mas seria relativizada pelo processo de esgotamento da doença com o aumento da resistência da população pós-epidemia. Sendo assim, nạao teria ocorrido na segunda metade do século XIX uma melhoria do padrão de vida significativamente maior em relação ao início do séclo XX, como aponta o trabalho de Ruffino \& Pereira. 
Esta discussão em torno das especulações sobre a tendência secular da mortalidade por tuberculose visa ressaltar a importância de um maior refinamento das hipóteses explicativas sobre o processo de saúde e doença de uma formação social.

Como ressalta Laurell, as evidências empíricas demonstram que existe uma relação entre o processo social e o processo saúde e doença, porém falta ainda esclarecer qual o caráter desta relação e quais as suas particularidades que são ao mesmo tempo sociais e biológicas. (7)

Apesar do avanço dos estudos epidemiológicos recentes no aprofundamento desta questão, este é um dos principais impasses teóricos da epidemiologia social.

This paper aims to review a discussion held by many authors on the secular tendency regarding the mortality of tuberculosis in different social formations. We observed that there was an agreement among the authors concerning 1) the influence of the improvement of the standard of living of the populations in the fall of the mortality related to the disease, and 2) the acceleration of this fall from the introduction of effective chemotherapy. Many authors also consider the hypothesis that an epidemic of the disease occured in the beginning of the 19th century in places such as England and Rio de Janeiro City via clearly distinct social conditioners, while there are others who do not work with this hypothesis in their attempts to explain the fluctuations in the "secular tendency" of the disease.

\section{REFERÊNCIAS BIBLIOGRÁFICAS}

1. BERLINGUER, G. Medicina e Política. São Paulo, CEBES/ HUCITEC, 1978, p. 52.

2. COCKBURN, A, M. D. The Evolution and Eradication of Infections Diseases, Baltimore, The John Hopkins Press, 1963.

3. DUBOS, R. \& J. The White Plague - Tuberculosis Man and Society. Boston, Little Brown and Company, 1952.

4. GRIGG, E. R. N. "The Areana of Tuberculosis III. Epidemiologic History of Tuberculosis in the United States", Am. Rev. Tuber. Pulm. Dis., 78 (3): 426-453, sept. 1958.

5. GUIMAR ÄES, R. "Determinaçăo Social e Doença Endêmica. O caso da Tuberculose", Textos de Apoio. Epidemiologia 1. Rio de Janeiro, PEC/ENSP, 1985, p. 211-33.

6. HOBSBA WN, J. E. Os Trabalhadores. Rio de Janeiro, Paz e Terra, 1981.

Cadernos de Saúde Pública, RJ, 4 (4): 398-406, out/dez, 1988 
7. LAURELL, A. C. "A Saúde-Doença como processo social". In: NUNUS, E. D. org. Medicina Social Aspectos Históricos e Teóricos. São Paulo. Global ed. 1983.

8. MCKEOWN, T. \& LOWE, C. R. Introducción a la Medicina Social, México, Siglo Veintiuno, 1981, p. 22-24.

9. MCKEOWN, T. The Role of Medicine: Dream, Mirage or Nemesis? New Jersey, Princeton University Press 1979, p. 48.

10. RUFFINO, A. N. \& PEREIRA, J. C. "Mortalidade por Tuberculose e Condiçōes de Vida: O Caso do Rio de Janeiro", Saúde em Dehate. Rio de Janeiro (12): 27-34, 1981. 